\title{
High Performance Computing Data Center
}

The new high performance computing (HPC) data center in NREL's Energy Systems Integration Facility (ESIF) is designed to be one of the most energy efficient data centers in the world, featuring warm water liquid cooling and waste heat capture and re-use. It's HPC capabilities will support the breadth of research at NREL, leading to increased efficiency and lower costs for important technologies including solar photovoltaics, wind energy, energy storage, electric vehicles, and the large-scale integration of renewables with the Smart Grid.

With state-of-the-art computational modeling and predictive simulation capabilities, the HPC data center will reduce the risks and uncertainty that are often barriers to industry adopting new and innovative technologies, thereby accelerating the transformation or our nation's energy system.

\section{Energy Efficient Supercomputing}

Initially, the HPC data center will house a petascale computing capability (one million billion calculations per second) and provide room for future systems that enable largescale modeling and simulation of novel materials, biological and chemical processes, and fully integrated systems that would be too expensive, or even impossible, to study by direct experimentation. Not only will NREL's data center house the fastest HPC system in the world dedicated to advancing energy efficiency and renewable energy technologies, it will also be one of the most energy efficient data centers in the world, operating at a power usage effectiveness (PUE) rating of 1.06 or better.

\section{A 2006 study conducted by the U.S.}

Environmental Protection Agency estimated that data centers account for about $2 \%$ of all electricity consumed in the U.S. alone-roughly equivalent to the energy used by the entire airline industry. What's more, the industry is in the midst of the biggest build-out of new data center capacity in its history, therefore, improving energy efficiency in data center designs is critically important. NREL's HPC data center in the ESIF will be a showcase data center facility demonstrating best-in-class technologies for a holistic, integrated approach to energy efficient high performance computing.

\section{Innovative Cooling Design}

Traditional data centers circulate mechanically cooled air (typically $50^{\circ} \mathrm{F}$ ) under pressurized raised floors up through grated floor tiles in front of the compute racks in an attempt to keep vital computer chips from going above $150^{\circ} \mathrm{F}$. The new ESIF data center will take advantage of the fact that liquid has approximately 1000 times the cooling capacity of air and pumps circulating liquid cooling are much more efficient than fans circulating air. The primary means for keeping the HPC systems in the data center from overheating is a liquid-cooled approach-warm liquid, that is.

The working fluid will start at approximately $75^{\circ} \mathrm{F}$. It will circulate through heat exchangers in the HPC system to efficiently capture waste heat from the HPC system. The liquid will be heated to $95^{\circ} \mathrm{F}$ or warmer by the HPC system and be utilized as the primary source of heating for laboratory and office spaces in the ESIF. Provisions have been made to export heat beyond the ESIF to the rest of the campus. Data center waste heat will even be circulated through piping under walkways to keep pedestrian areas free of dangerous ice and snow in cold months. Reuse of the data center waste heat also saves water cooling tower water. Data center waste heat not needed by the building can be rejected via efficient evaporative cooling towers serving the HPC data center.
The ESIF HPC data center is approximately 10,000 $\mathrm{sf}^{2}$ of uninterrupted, usable machine room space and is designed to be ultra energy efficient, capturing both the critical bytes of information for scientific research as well as the heat generated by powering multi-megawatts of HPC equipment, then used to heat office and laboratory space in the new facility.

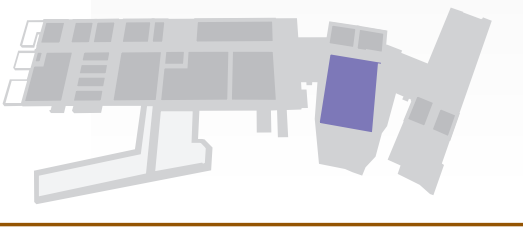




\section{INFORMATION CIRCULATION COLLABORATION}

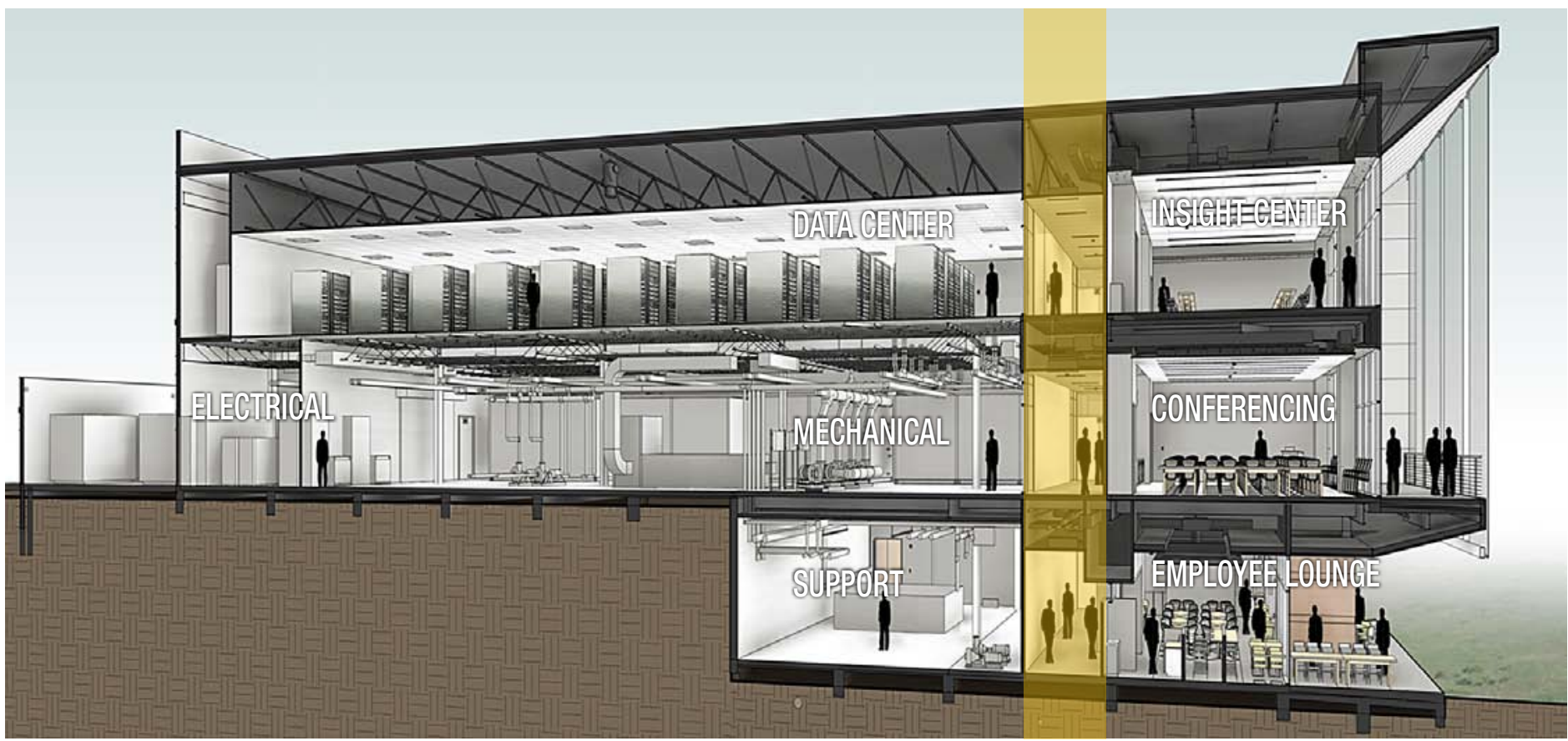

Cross section view into the ESIF HPC data center. IIlustration from Smith GroupJJR

\section{Innovative Building Design}

The top floor has approximately $10,000 \mathrm{sf}^{2}$ of uninterrupted, usable machine room space to house HPC and related equipment. The data center ceiling height is 11 feet, with return openings as required for any residual data center heat not captured to the hydronic cooling system. Return air chases on the north and south direct warm air from the ceiling plenum above down to the main fan wall air-handling units below. The middle floor is the mechanical space for pumps and power distribution. The lowest level is a pump room that allows the ESIF to connect to central heating and cooling services as needed for backup or to supply heat to other parts of the NREL campus.

Tour corridors with large viewing window areas are on all three floors. All major components of the mechanical and electrical system will be color coded to identify the role they play in this energy efficient infrastructure and will be viewable from the tour routes. The stacked nature of the data center provides for a very compact design resulting in short run lengths for both electrical and plumbing components. Data center efficiency will be highlighted with LED monitors at the viewing windows reporting instantaneous, season, and cumulative values for PUE and energy re-use.

\section{Partner with Us}

Work with NREL experts and take advantage of the state-of-the-art capabilities at the ESIF to make progress on your innovative research in computational science, mathematics, and scientific computing.

Partners at the ESIF's High Performance Computing Data Center may include:

- Researchers and scientists

- Visualization software developers

- Energy manufacturers and investors

- Utilities

- Government agencies

- Universities

- Other National laboratories

\section{Contact Us}

If you are interested in working with NREL's High Performance Data Computing Center, please contact:

\section{Steven W. Hammond, Director Computational Science Center Steven.Hammond@nrel.gov 303-275-4121}

Top front page photo from istock/03364509. IIlustration from Smith GroupJJR

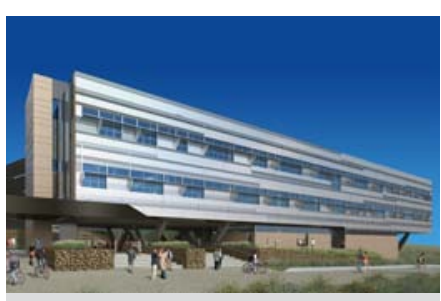

The Energy Systems Integration Facility (ESIF) will be one of the only megawatt-scale test facilities in the United States that integrates electricity, thermal, and fuel systems with high performance modeling and simulation capabilities.

NREL scientists and engineers at the ESIF will research and test integrated energy systems, devices, and concepts for electric supply and demand systems.

For more information on the ESIF and to take an online tour of the laboratories of the ESIF, visit www.nrel.gov/esi/ esif.html.

Illustration from Smith GroupJJR
National Renewable Energy Laboratory 15013 Denver West Parkway, Golden, CO 80401 303-275-3000 • www.nrel.gov
NREL is a national laboratory of the U.S. Department of Energy

Office of Energy Efficiency and Renewable Energy

Operated by the Alliance for Sustainable Energy, LLC

NREL/FS-5500-55423 • August 2012 